\title{
Congenital bilateral absence of vas deferens
}

INSERM

\section{Source}

INSERM. (1999). Orphanet: an online rare disease and orphan drug data base. Congenital bilateral absence of vas deferens. ORPHA:48

Congenital bilateral absence of the vas deferens (CBAVD) is a condition leading to male infertility. 